Article

\title{
Performance of Maraging Steel Sleeves Produced by SLM with Subsequent Age Hardening
}

\author{
Piotr Tyczyński ${ }^{1}$, Zbigniew Siemiątkowski ${ }^{2}$ (D) Piotr Bąk ${ }^{3}$, Krzysztof Warzocha ${ }^{3}$, \\ Mirosław Rucki ${ }^{2}$ (D) and Tadeusz Szumiata ${ }^{2, *(D)}$ \\ 1 Mapal Narzędzia Precyzyjne Sp. z o.o., ul. Partyzancka 11, 61-495 Poznan, Poland; \\ Piotr.Tyczynski@mapal.com \\ 2 Faculty of Mechanical Engineering, Kazimierz Pulaski University of Technology and Humanities in Radom, \\ Krasickiego Str. 54, 26-600 Radom, Poland; z.siemiatkowski@uthrad.pl (Z.S.); m.rucki@uthrad.pl (M.R.) \\ 3 Yasa Motors Poland Sp. z o.o. S.K.A., ul. Wojska Polskiego 20, 39-300 Mielec, Poland; \\ piotr.bak@yasa-motors.com (P.B.); krzysztof.warzocha@yasa-motors.com (K.W.) \\ * Correspondence: t.szumiata@uthrad.pl
}

Received: 5 July 2020; Accepted: 29 July 2020; Published: 2 August 2020

check for updates

\begin{abstract}
In the paper, the researches on sleeves made out of maraging steel 1.2709 using selective laser melting (SLM) technology are presented. This additive technology is recognized as favorable for the environment, due to $100 \%$ use of material and durability of manufactured details. The fabricated sleeves underwent subsequent tests, in particular, microhardness, porosity and homogeneity of the material was examined before and after heat treatment and salt bath nitrocarburizing process. Two kinds of fatigue tests were performed. The first consisted of the typical sinusoidal alternating load, the other was the high pressure pulse load test close to the real work conditions. It is of high importance that the fatigue strength of the tested sleeves is considerably higher than that of the similarly produced details shaped as a standard samples for tensile stress. The Mössbauer spectrometry analysis of hyperfine magnetic field distributions proved that SLM did not change considerably the martensite structure at atomic level.
\end{abstract}

Keywords: additive manufacturing; pro-environmental technologies; selective laser melting; porosity; fatigue; hyperfine magnetic field

\section{Introduction}

The manufacturing costs of a given part increase along with the amount of material that needs to be cut until the finished product is complete. Additive manufacturing (AM) technology allows for a total reduction of material waste and does not require prepping semi-finished products, which usually generates additional costs. Manufacturing of net-shape functional components [1] or thin-walled components for aerospace industry [2], are good examples for benefits resulting from AM applications.

The main materials available for this process are: aluminum AlSi10Mg, cobalt chrome alloy Co28Cr6Mo, nickel alloy In718, maraging steel 1.2709, 316L stainless steel, 15-5PH stainless steel, titanium alloy Ti6Al4V, commercially pure titanium TiCP. The powders for further selective laser melting (SLM) process are produced using a gas atomization process and at the moment are predominantly generated as a by-product of other powder generation processes. As a result, powders are currently very expensive compared to other powders (namely aluminum powder used in the spray paint industry). A recent review of process parameters for SLM of Ti-6Al-4V was published by Shipley et al. [3], while Doubenskaia et al. [4] applied an integral analysis and presented results of a study on SLM process of intermetallic TiAl powder. Xia et al. [5] reported the results on researches on porosity 
evolution during SLM process of Inconel 718 alloy. Other team proposed X-ray CT method for discontinuity and porosity detection in the parts produced with SLM technology [6].

The present study is focused to analyze the maraging steel 1.2709 using SML technology that proved good results in tools fabrication [7]. The resulted material usually underwent further treatment in order to achieve desired shape or surface quality, as described by many researchers, e.g., [8] and [9]. Some scholars reported interesting results on general microstructure and mechanical properties of this material after SLM process and post heat treatment. It was reported that the quantity of austenite phase in maraging steel increased during aging treatment due to reversion of martensite to austenite [10]. Others examined its tensile, fracture, and fatigue strength and came to the conclusion that the overall mechanical performance, including the fatigue crack growth characteristics, of the SLM maraging steel after aging was similar to that of conventionally manufactured MS of the same grade [11]. It was found that the fatigue behavior of the SLM-processed austenitic steel AISI $316 \mathrm{~L}$ was strongly related to the building direction, leading to a reduction of fatigue life [12]. In case of bi-material specimens manufactured by SLM, the failure occurred in the material near the interface [13]. The influence of powder layer thickness on the quality of SLM printed parts was also studied [14]. It is expected that the fatigue behavior of the SLM-processed maraging steel will be dependent on defects, residual stresses, surface finish, geometry and size, layer orientation, and heat treatment, as it was demonstrated experimentally in case of Ti-6Al-4V alloy [15].

One of the most common processes applied to the maraging steel 1.2709 is the age hardening [16]. In the present study, we applied also a salt bath nitrocarburizing process afterwards, and performed analysis of structure and strength of the material. Apart from typical tensile tests two kinds of fatigue tests were made. The results are very important because in case of sleeves, one-sided tensile fatigue load is substantially different from the hoop stress in real work conditions, which was not addressed in previous publications.

\section{Materials and Methods}

The researches were aimed at a feasibility study on application of additive manufacturing, in particular SLM, to produce the sleeve type parts for hydraulic actuators, such as a fly-by-wire (FBW) actuator. The study involved tests on porosity, hardness, and fatigue strength of the final product material, as well as Mössbauer analysis of the components for rough powder sample and for the fabricated sleeve.

\subsection{Characterization of the Examined Details}

The test samples were made by AM technology (SLM), where metal powder plays a very important role. Quality of the applied metal powder has a major influence on mechanical properties of the produced detail, but it can also have impact on the build-to-build consistency, the reproducibility between AM machines, the production of defect-free components, the manufacturing defects on surfaces [17]. In the experiments, maraging steel (material 1.2709) powder produced by LPW Technology Ltd., Cheshire, UK, was applied.

The scheme and general view of the tested sleeves are shown in Figures 1 and 2 demonstrate the differences between the three types of the tested sleeves with wall thicknesses $a_{1}=0.6, a_{2}=0.5$ and $a_{3}=0.4 \mathrm{~mm}$, respectively.

According to the producer's specification, the chemical composition was as follows: Fe (balance), $\mathrm{Ni}(17-19 \mathrm{wt} \%), \mathrm{Co}(8.5-9.5 \mathrm{wt} \%), \mathrm{Mo}(4.5-5.2 \mathrm{wt} \%), \mathrm{Ti}(0.6-0.8 \mathrm{wt} \%), \mathrm{Al}(0.05-0.15 \mathrm{wt} \%), \mathrm{Cr}$ and $\mathrm{Cu}$ (each $\leq 0.5 \mathrm{wt} \%), \mathrm{C}(\leq 0.03 \mathrm{wt} \%), \mathrm{Mn}$ and $\mathrm{Si}($ each $\leq 0.1 \mathrm{wt} \%), \mathrm{P}$ and $\mathrm{S}$ (each $\leq 0.01 \mathrm{wt} \%)$.

Density of bulk material 1.2709 is $\rho \approx 8.0-8.1 \mathrm{~g} / \mathrm{cm}^{3}$. The initial material was powdered down to $43 \mu \mathrm{m}$ particle diameter as a $90 \%$ prevailing fraction seen in scanning electron microscope (SEM) image in Figure 3.

Analyses were prepared and performed according to the standards EN ISO 945-1, ASMT A247, JIS G5502, KS D 4302, GB/T 9441. All the samples for further experimental researches were printed on a 3D printer ReaLizer SLM250, made by REALIZER, Borchen, Germany. 


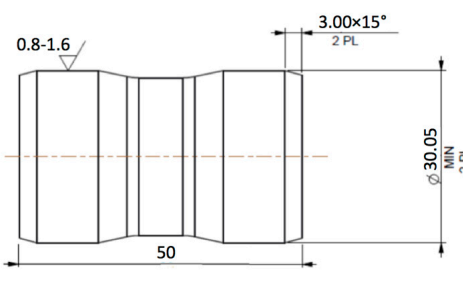

(a)

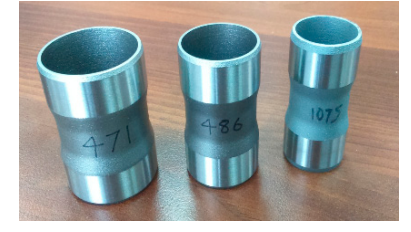

(b)

Figure 1. Details produced by AM technology for tests: (a) scheme; (b) photograph.
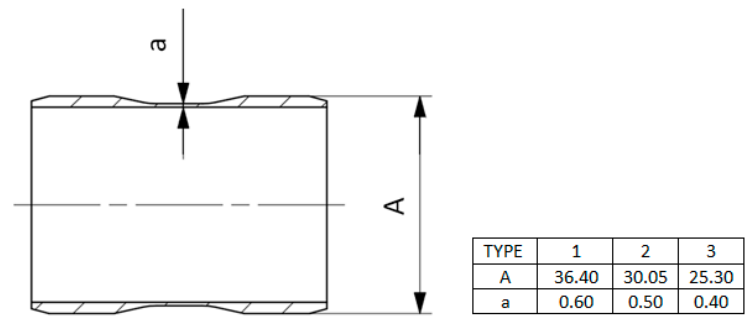

Figure 2. Dimensions of the three types of sleeves produced by AM technology for tests.

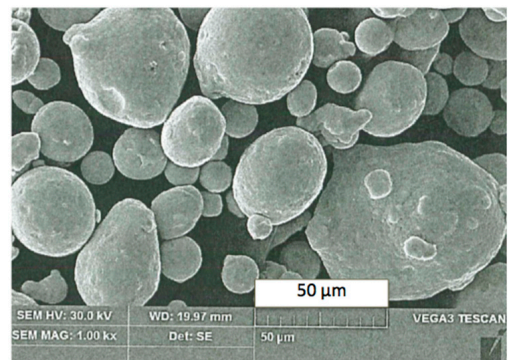

Figure 3. SEM image of the powdered steel 1.2709.

The process took place in protective gas atmosphere (argon), with maximum oxygen amount $0.3 \%$. Base plate temperature was $80^{\circ} \mathrm{C}$. The samples were arranged on the plate as shown in Figure $4 \mathrm{a}$, where supportive elements are shown in yellow red color and marked with arrow. These supporting structures shown in detail in Figure $4 \mathrm{~b}$ allow for supporting steep overhangs and cantilevered sections of the model as it is built layer by layer. They are thin-walled, light and easy to remove structures, which help to avoid unnecessary material waste.

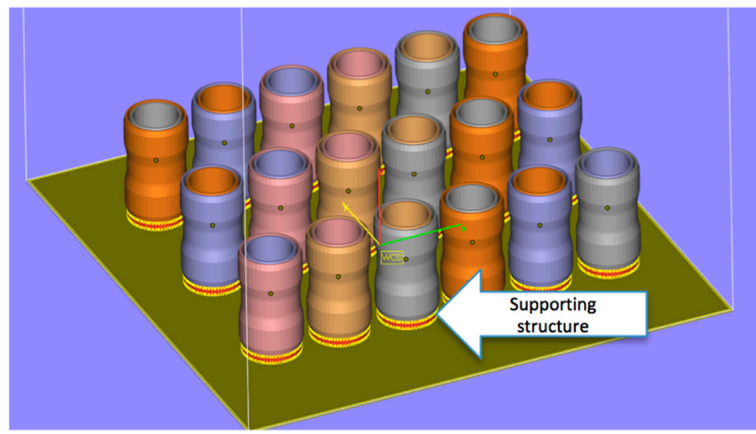

(a)

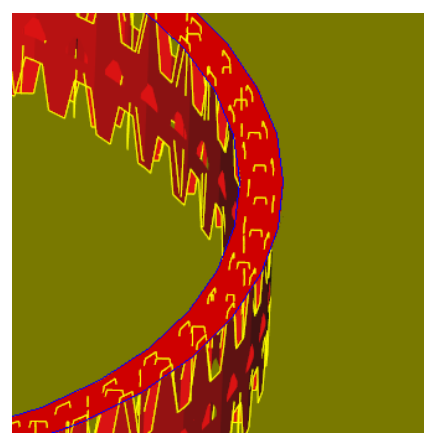

(b)

Figure 4. Arrangement of the samples in the 3D printer space: (a) overview; (b) example of supportive structure.

Among others, supportive elements are responsible for the proper heat removal. Thus, they have impact on the microstructure of the material. 


\subsection{Porosity and Microhardness}

The research was aimed to analyze the porosity of material, so the percentage of pores in the volume of material produced by AM technology was measured. To achieve that, a series of samples underwent impregnation and polishing, as shown in the Figure 5.

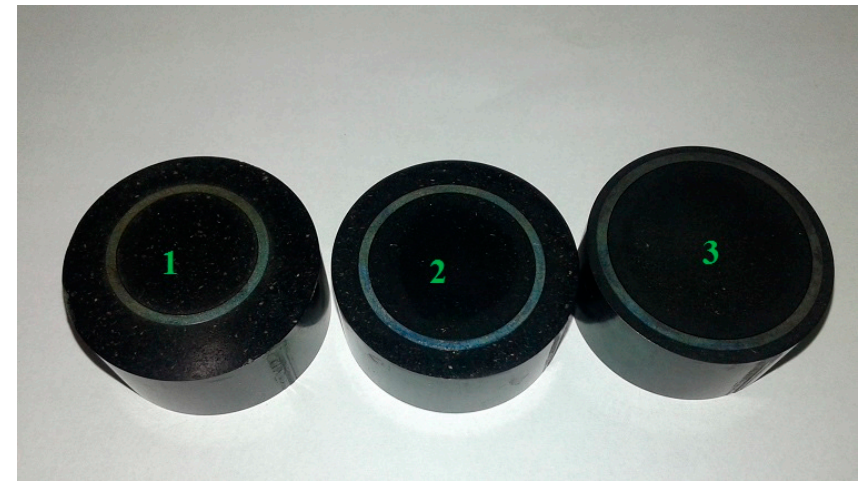

(a)

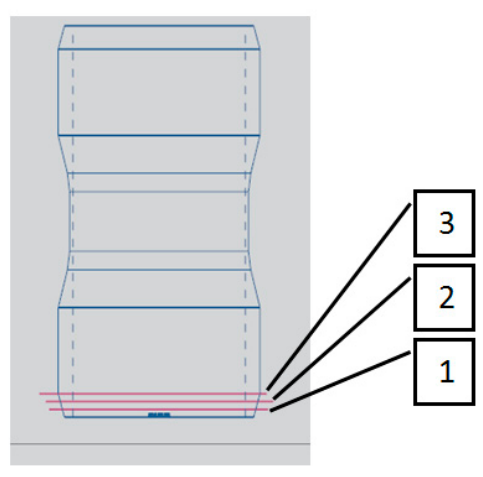

(b)

Figure 5. Metallographic test surfaces (a) and theirposition in the sleeve (b).

Metallographic analysis was performed using the optical microscope Olympus BX51M (Olympus Corporation, Tokyo, Japan). The device allowed to analyze the images in white light, in reversed light, in polarized light, as well as in the interference contrast and in reflected light. The microscope was equipped with Koehler lighting system that ensures steady, stable and shadeless exposition of the sample surface, with smooth regulation in the entire range. Camera adapter enabled to make photos and acquisition, archiving and morphometric measurements. In order to measure percentage of the pores in the material structure, the dedicated software Olympus Stream Essentials was employed.

Hardness measurement of the 3D printed samples made of 1.2709 steel was performed using the device Qness Q250MS type (Qness Gmbh, Golling, Austria). It enabled to measure the Brinell hardness (DIN EN ISO 6506), Vickers hardness (DIN EN ISO 6506), Rockwell hardness (DIN EN ISO 6508) and Koop microhardness (DIN EN ISO 4545). The images of the test impressions are evaluated fully automatically using automatic brightness control and an autofocus camera to guarantee maximum process reliability. In the current research, the methods HV1, HV0.5 and HV0.1 were applied.

\subsection{Fatigue Test Methodology}

Apart from standard tensile testing procedure (PN-EN ISO 6892-1:2016-09, device Instron 3382), series of the experiments were performed in order to evaluate strength and fatigue resistance of materials. In the laboratory of Rzeszow University of Technology, Rzeszow, Poland, typical fatigue tests were performed. Sample made of the steel 1.2709 with AM technology had round intersections and dimensions in accordance with the standard ASTM E466-15. It was produced using SLM method with similar parameters as the examined sleeves, with layers added in the longitudinal direction. No surface machining was applied, only abrasive blasting was used to clean the surface before and after heat treatment. The exception was the surface of fixation to the device, which was machined but had no impact on the measurement results. The test was performed with the dedicated device INSTRON 8801 (Instron, Norwood, MA, USA) at room temperature.

The samples underwent the sinusoidal alternating load with frequency $f=3 \mathrm{~Hz}$ in conditions of one-sided tensile testing, where the tensions did not change their direction. Amplitude of the tensions is determined by the difference between their highest and lowest values, $\sigma_{\max }$ and $\sigma_{\min }$, respectively:

$$
\sigma_{a}=\frac{\sigma_{\max }-\sigma_{\min }}{2}
$$


Thus, the range of the tension's variation was $\Delta \sigma=2 \sigma_{a}=\sigma_{\max }-\sigma_{\min }$. The cycle asymmetry factor was $R=\sigma_{\min } / \sigma_{\max }=0.05$.

Since the layer-by-layer laser melting technology generates specific structure dependent on the shape and destination of the part, it reveals anisotropic fatigue performance dependent of the build direction [18]. Thus, another kind of fatigue resistance was related to the real work conditions of the sleeves produced with AM technology. Figure 6 presents the examples of hoop stress distribution and deformation in the tested details simulated by Finite Elements Method (FEM).

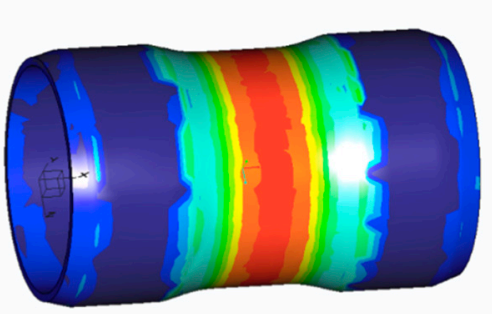

(a)
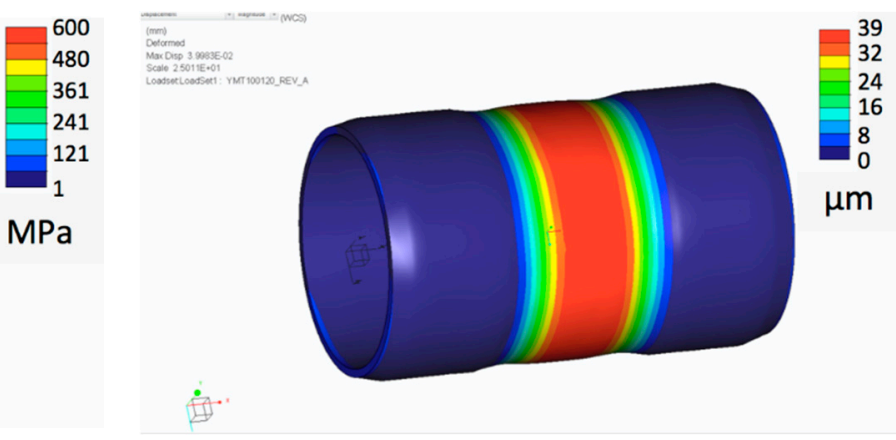

(b)

Figure 6. Examples of FEM simulation: (a) stress distribution; (b) deformations.

The hoop stress, also referred to as circumferential or tangential stress, is defined as follows [19]:

$$
\sigma_{h}=\frac{P D}{2 a}
$$

where $P$ is design pressure, $D$-outside diameter, $a$-pipe wall thickness. In the experimental research, the samples were prepared with diameters $D_{1}=34.20, D_{2}=28.00$ and $D_{3}=22.88 \mathrm{~mm}$, and respective wall thickness of $a_{1}=0.60, a_{2}=0.50$ and $a_{3}=0.40 \mathrm{~mm}$.

The experimental rig was built for the high pressure pulse load tests. The maximal pressure load obtainable in the test rig was $5000 \mathrm{psi}(35 \mathrm{MPa})$, and the safety system stops the procedure when the sample is destroyed. The latter is indicated by the presence of oil outside the tested sleeve in the sink unit. During the work, the system generates pressure $P$ pulses with period of ca. $0.2 \mathrm{~s}$. The pressure transducer connected with oscilloscope enables to check the parameter of the pressure pulses. Example of the pressure indications registered by the oscilloscope is shown in Figure 7.

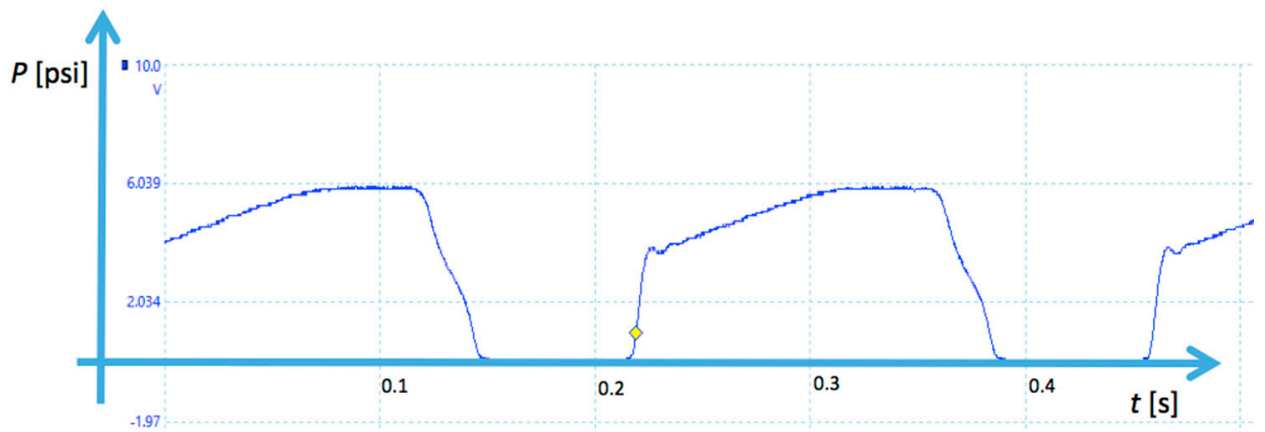

Figure 7. Example of pressure pulses registered by oscilloscope.

Working value of the pressure $P=35 \mathrm{MPa}$ was reached by the regulator and set with accuracy of $\pm 2 \%$. The pressure should be checked and adjusted after the oil is heated. It was noted that the pressure dropped a little after some time, when the oil temperature became higher. Obtained pressure signal must be repeatable in its minimal and maximal values. 


\subsection{Mössbauer Spectrometer System, Fitting Methods and Samples Preparation}

${ }^{57} \mathrm{Fe}$ Mössbauer spectrometer for iron-containing phases investigations produced by Polon, Poland, and modernized at University of Technology and Humanities (UTH) in Radom, Poland, was arranged in vertical configuration. It was equipped with ${ }^{57} \mathrm{Co}(\mathrm{Rh}) \gamma$-ray source and was operating in constant acceleration mode. Fitting of the Mössbauer spectra was performed by means of PolMoss v2.0 MulticoreTab software (by Tadeusz Szumiata, UTH, Radom, Poland) which is a package based on MS Excel and Solver optimizing module with gradient and genetic algorithms. This software was successfully utilized in the case both of the steel [20] and environmental samples [21]. Recently, it was updated for better performance of parallel calculations on multicore processors. PolMoss package provides a convolution of the Lorentzian baseline with Gaussian distributions of hyperfine parameters. This results in Voigt profile of fitted subspectra. The procedure of the convolution has been realized as numerical summation of finite number of Zeeman sextets scaled by discrete Gaussian distribution. Two samples for transmission Mössbauer measurements at room temperature were in the form of powders. The first one was just an initial powder, and the second one-shavings of sleeve filed with a ceramic file.

\section{Results and Discussion}

The obtained experimental results are presented and discussed in three groups: porosity and microhardness, fatigue strength and Mössbauer results, respectively.

\subsection{Porosity and Microhardness}

Figure 8 presents the example of the images obtained in the respective intersections 1, 2 and 3 explained in the Figure 5 above. The samples were etched with nital 1\%, red stains represent pores. Analysis provided the information that the material in intersection 1 (Figure $9 a$ ) had $3.43 \%$ of the pores. This intersection corresponds with the layers adjacent to the supportive structure that were formed in the very beginning of the AM process. Subsequent analyzed intersections were formed later, as they are placed above the level 1 . It is clearly seen in the Figure $9 b, c$, that number and dimensions of pores are smaller and smaller for the layers 2 and 3 , which was confirmed by the measurement. The analysis revealed pores percentage of $1.24 \%$ and $0.56 \%$ for the intersections 2 and 3, respectively.

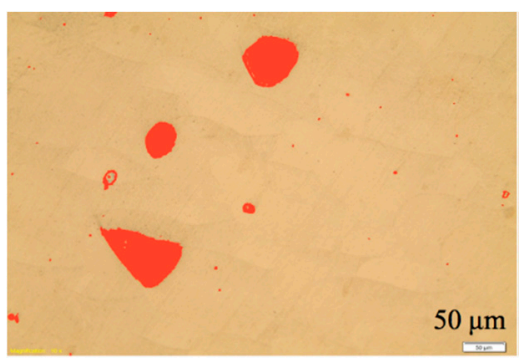

(a)

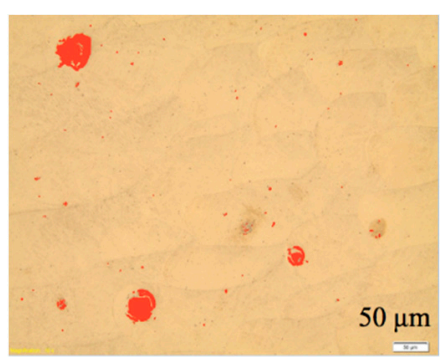

(b)

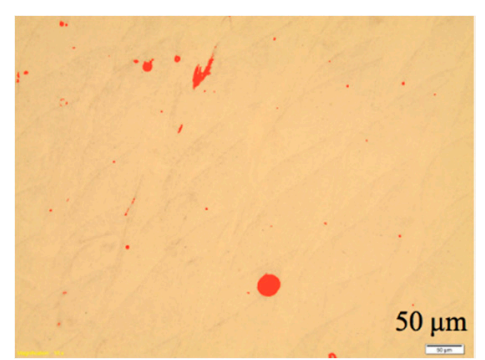

(c)

Figure 8. Analysis of the pores percentage in the respective intersections as explained in the Figure 5: (a) intersection 1 ; (b) intersection 2; (c) intersection 3.

Moreover, in the material layers adjacent to the supportive structure that was to be removed, some unmolten powder particles were found. They were encapsulated together and surrounded with the material as shown in the photomicrograph in Figure 9a. On the other hand, the structure became stabilized above intersection 3 , and revealed porosity close to $0.56 \%$. Figure $9 \mathrm{~b}$ presents an example of the microstructure in intersection 3 as it was explained in the Figure 5 above.

The microstructure seen in the Figure $9 \mathrm{~b}$ exposes cellular structure with high uniformity of grains. It should be noted, however, that the bulk material grains do not reflect the size of "primary" powder particles. Martensite grains dimensions are between 0.5 and $1 \mu \mathrm{m}$, and they adhere closely to one 
another in the environment of retained austenite. At $2000 \times$ zoom, just few paths can be noted, where grains are not in close contact. Structural uniformity largely contributes to the material strength.

At the next stage of the research, the measurements of microhardness of core and surface layer were performed. In the experiments, three groups of samples were used. First group constituted the samples right after the 3D printing, with no additional operations that would improve uniformity of the structure. The second group consisted of the samples after dedicated heat treatment, specific for 1.2709 steel (so-called precipitation hardening or age hardening [22]). And to the third group belonged samples that after age hardening underwent also thermochemical modification by salt bath nitrocarburizing known as TENIFER process [23] that may have different impact on different materials [24]. The experiments were projected in the way that would enable to qualify the usefulness of abovementioned processes in further production of the specific details with AM technology considering their destinations, strength, fatigue resistance and other mechanical and physical properties. Especially in case of aerospace industry, importance of each part's reliability is crucial.

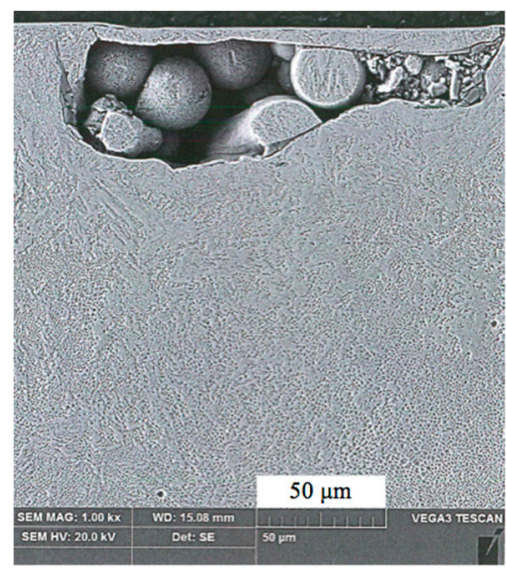

(a)

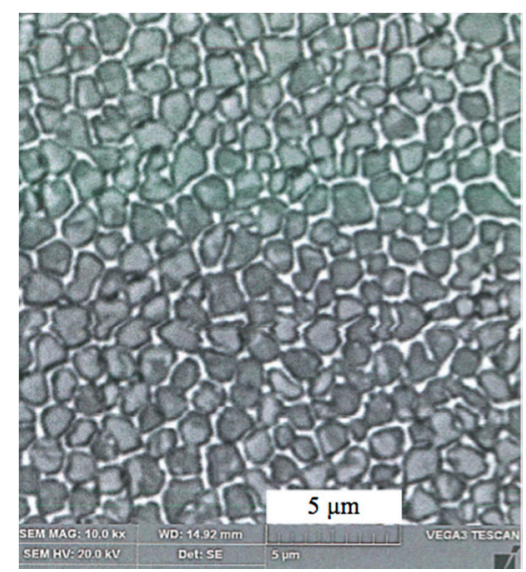

(b)

Figure 9. SEM images of microstructure: (a) example of the unmolten particles; (b) grained microstructure of the sample 3.

In the experiments, precipitation hardening took place without any inertial gas shielding. The samples were heated in temperature $490^{\circ} \mathrm{C}$ for $6 \mathrm{~h}$, and then cooled down freely in normal ambient conditions. After that, samples from the third group were sent to the laboratory where complete salt bath nitrocarburizing process Quench-Polish-Quench (QPQ) was performed [25]. According to the procedure, the parts were first preheated to about $350{ }^{\circ} \mathrm{C}$ in air, and then put into so-called TF1 bath, consisting of alkali cyanate and alkali carbonate salt melt, at temperature $580{ }^{\circ} \mathrm{C}$. Next, the samples were cooled down in a specially developed so-called AB1 bath at about $400{ }^{\circ} \mathrm{C}$. Then, after being cooled to the room temperature, the samples were cleaned and polished, completing QP process (Quench-Polish), and underwent oxidative post treatment in the same salt melt and the same temperature finishing the entire QPQ process. The post-oxidation was aimed to restore some partial loose of the corrosion resistance after polishing.

Figure 10a-c presents examples of SEM image of the structures obtained in the sample that belonged to the respective groups 1, 2 and 3. In case of group 3, the surface layer modified by TENIFER process is clearly distinguishable in Figure 10c. In order to emphasize the modified layer, the samples were etched with nital, an example of the photomicrograph is shown in Figure 11.

The sample from the group 3 shown in SEM image in Figure 10c exposes grains prolonged in the direction perpendicular to the surface. No such effect can be seen both in the samples of group 1 (without heat treatment) and of group 2 (after age hardening but without TENIFER), shown in Figure 10a,b. Measurement performed with the photomicrograph provided information that the nitrogen diffusion layer was of depth ca. $68 \mu \mathrm{m}$. However, the actual nitrogen penetration depth 
and the respective nitriding hardness depth are pending to be considerably higher than the visible etchable dark area [25]. As it is demonstrated below, hardness measurement has confirmed substantial structural changes. The results are presented in the Table 1.

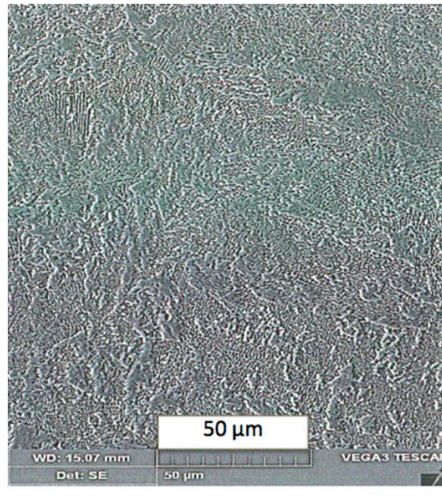

(a)

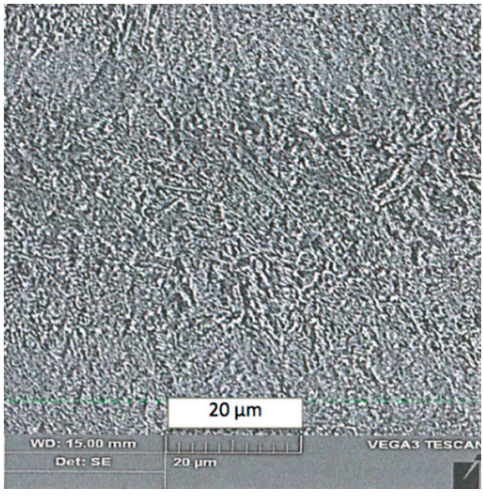

(b)

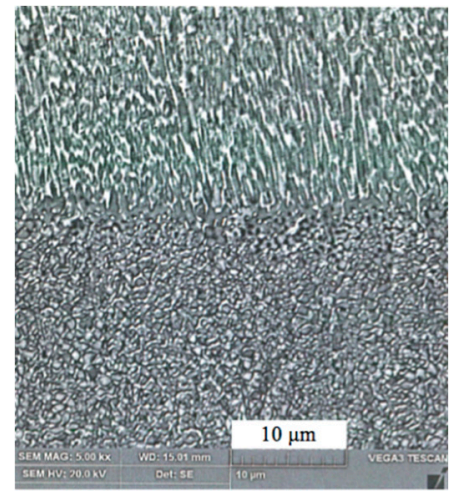

(c)

Figure 10. The SEM image of samples of different groups: (a) group1; (b) group 2; (c) group 3.

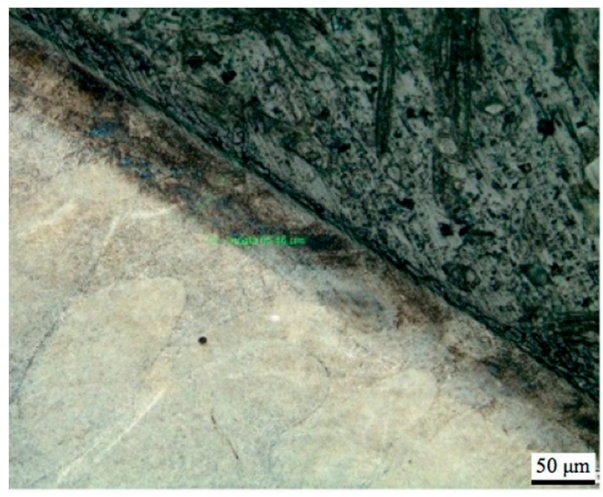

Figure 11. Photomicrograph of the sample of group 3.

Table 1. Microhardness measurement results.

\begin{tabular}{cccc}
\hline No. & $\begin{array}{c}\text { Group 1 } \\
\text { (Without Heat Treatment) } \\
\text { Measurement Method HV0.1 }\end{array}$ & $\begin{array}{c}\text { Group 2 } \\
\text { (after Age Hardening but } \\
\text { Without TENIFER) } \\
\text { Measurement Method HV0.1 }\end{array}$ & $\begin{array}{c}\text { Group 3 } \\
\text { (after Age Hardening and TENIFER) } \\
\text { Measurement Method HV0.1 } \\
\text { (0.025 mm from Surface) }\end{array}$ \\
\hline 1 & $344 \mathrm{HV}$ & $420 \mathrm{HV}$ & $560 \mathrm{HV}$ \\
2 & $355 \mathrm{HV}$ & $397 \mathrm{HV}$ & $554 \mathrm{HV}$ \\
3 & $331 \mathrm{HV}$ & $389 \mathrm{HV}$ & $508 \mathrm{HV}$ \\
Standard deviation & 9.809 & 13.140 & 23.230 \\
\hline
\end{tabular}

The analysis proved that the precipitation hardening process (group 2) and subsequent surface treatment (group 3) provide the improvement of hardness according to the available steel 1.2709 specification. However, it is important to make more detailed insight to the third group results, since it underwent two subsequent processes, heat treatment and ferritic nitrocarburizing.

The nitrocarburised layer was subject of detailed measurement in order to determine its microhardness compared to the core material. The difficulties with microhardness distribution at the depth of the nitrocarburised layer rose because of its small thickness compared to the penetrator dents. For instance, when it was put too close to the edge of the sample, penetrator caused a crack seen in Figure 12a, which obviously affected the result of measurement. In case of sample 2, where visible nitrogen diffusion layer was just $40 \mu \mathrm{m}$ wide, the penetrator dent covered ca. $75 \%$ of its width, as it is seen in Figure 12b. Table 2 presents the results of measurement. 


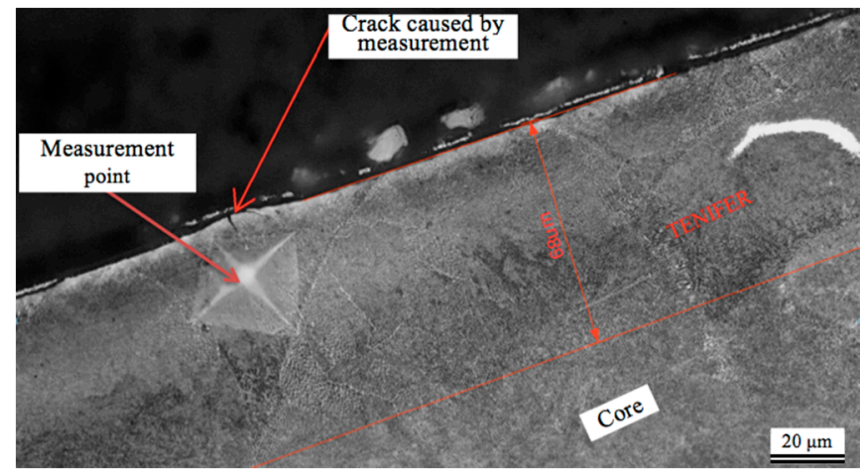

(a)

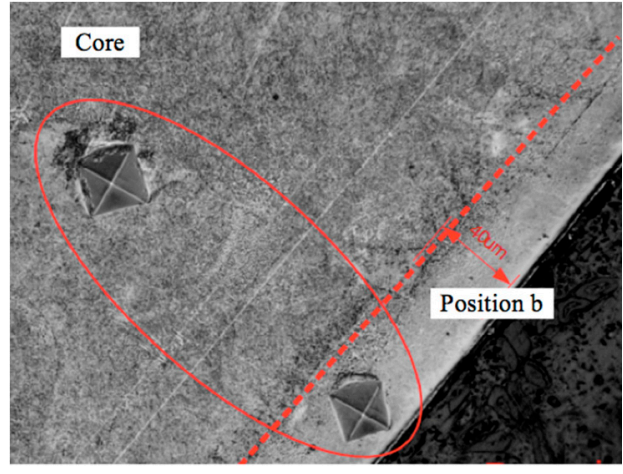

(b)

Figure 12. Photomicrograph of the microhardness measurement: (a) sample 1 with the measurement point $a$; (b) sample 2 with the measurement point $b$.

Table 2. Microhardness measurement results in different points.

\begin{tabular}{cccc}
\hline Sample No. & $\begin{array}{c}\text { Thickness of Modified Layer } \\
{[\mu \mathrm{m}]}\end{array}$ & $\begin{array}{c}\text { Hardness of Modified Layer in } \\
\text { Its Middle [HV 0.5] }\end{array}$ & $\begin{array}{c}\text { Hardness of Core (160 } \mu \mathrm{m} \text { from Surface) } \\
\text { [HV 0.5] }\end{array}$ \\
\hline Sample 1 point $a$ & 68.08 & 603 & 475 \\
Sample 2 point $b$ & 44.51 & 698 & 432 \\
Sample 3 point $c$ & 65.86 & 659 & 478 \\
\hline
\end{tabular}

As it is seen in the Table 2, hardness values HV0.5 for the TENIFER modified layer are 20-40\% larger than the ones for the core material.

\subsection{Fatigue Tests}

First of all, it should be noted that the static tensile testing revealed very large range of variation between the samples in the elongation expressed by engineering strain $\varepsilon$. All the samples were produced with orthogonal scanning strategy, which reduced residual stress and porosity [26]. The hatch spacing was $0.050 \mathrm{~mm}$ and each subsequent layer was directed perpendicularly to the previous one. The laser power was $350 \mathrm{~W}$ and scanning speed was $1000 \mathrm{~mm} / \mathrm{s}$. After being printed, the samples for static tensile tests were heated in temperature $490{ }^{\circ} \mathrm{C}$ for $6 \mathrm{~h}$, as it is recommended for maraging steels, to reach hardness $55 \mathrm{HRC}$ which corresponds with ca. $595 \mathrm{HV}$.

In the Table 3 , along with $0.2 \%$ offset yield strength R0.2 and maximum withstandable stress $R_{m}$, there are presented the values of fracture A [\%] are presented for different samples with respective "necking" or reduction in the diameter Z [\%]. The fracture A varies between $1.2 \%$ and $6.9 \%$, while diameter reduction $Z$ between 5\% and 21\%. Maximum withstandable stress $R_{m}$ varies between 1287 and $1603 \mathrm{MPa}$, i.e., in range of $20 \%$ of its maximal value $1603 \mathrm{MPa}$.

Table 3. Results of static tensile testing of 1.2709 steel samples (Instron 3382).

\begin{tabular}{ccccc}
\hline Sample No. & $\boldsymbol{R}_{\mathbf{0 . 2}}[\mathbf{M P a}]$ & $\boldsymbol{R}_{\boldsymbol{m}}$ [MPa] & $\boldsymbol{A}[\mathbf{\%}]$ & $\boldsymbol{Z}[\%]$ \\
\hline 1 & 1317 & 1432 & 2.9 & 18 \\
2 & 1359 & 1450 & 5.1 & 21 \\
3 & 1445 & 1530 & 4.4 & 21 \\
4 & 1309 & 1397 & 1.2 & 5 \\
5 & 1530 & 1603 & 2.8 & 13 \\
6 & 1338 & 1417 & 6.8 & 10 \\
7 & 1268 & 1336 & 2.8 & 5 \\
8 & 1259 & 1347 & 6.0 & 6 \\
9 & 1204 & 1287 & 4.8 & 8 \\
10 & 1442 & 1514 & 6.9 & 13 \\
\hline
\end{tabular}


The abovementioned variations can be attributed to the microstructure differences generated by the layer-by-layer melting technology. Despite any procedures aimed to make the microstructure uniform, it remained distinguishably layered. It might be expected that a degree of transverse strain anisotropy was likely to remain due to the fabrication history, which was reported for AM alloys [27]. Moreover, the presence of detrimental surface and subsurface defects could cause some scatter in the strength and fatigue test results [28]. Obtained $0.2 \%$ offset yield strength $R_{0.2}$ and maximum withstandable stress $R_{m}$ of the AM samples of maraging steel may be considered repeatable in the satisfactory range.

The results of the standard fatigue testing are shown graphically in Figure 13, where the logarithmic S-N plot is presented. The last two points with $\sigma_{\max }=210$ and $200 \mathrm{MPa}$, and respective $\sigma_{\min }=10.5$ and $10 \mathrm{MPa}$ correspond with $N_{f}=300,000$ cycles, after which the sample did not break.

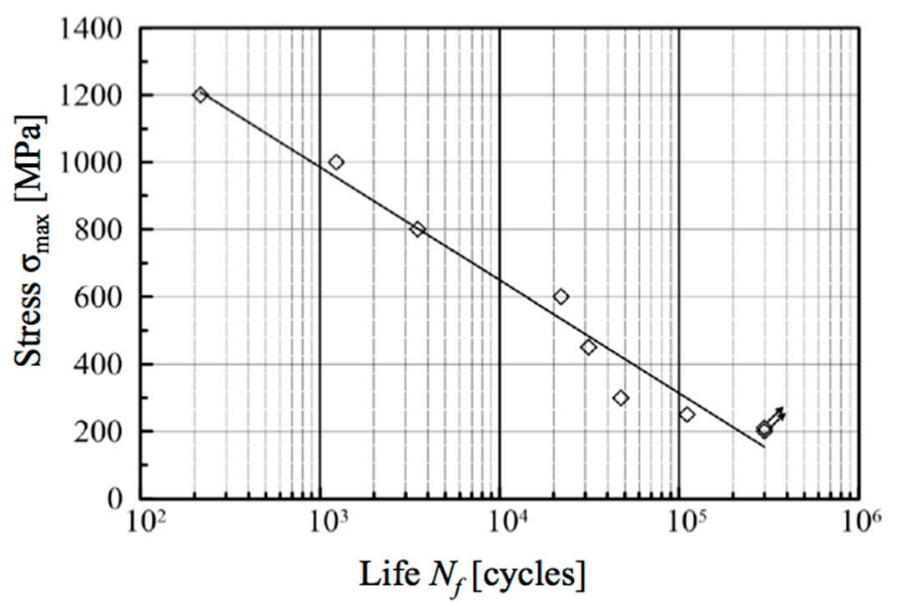

Figure 13. S-N logarithmic plot of one-sided tensile testing for fatigue strength of material 1.2709.

It should be noted that the maximal stress below $250 \mathrm{MPa}$ did not cause destruction of the samples after 300,000 of cycles. Thus, it can be assumed that for the larger number of cycles than $N_{g}=300,000$, the fatigue strength of the steel 1.2709 in the one-sided tensile test conditions $(R=0.05)$ can be expected to reach $210-250 \mathrm{MPa}$.

These findings are important especially in comparison with the results obtained for the hoop stress measured in the sleeves. In that case, 300,000 cycles corresponded with stress $\sigma_{\max }=371 \mathrm{MPa}$ (sample X0951). The stress values below $350 \mathrm{MPa}$ were bearable even for million cycles without failure, and data from 6 samples confirmed it (each of two samples with wall thickness $a_{1}=0.6$, two with $a_{2}=0.5$ and two with $a_{3}=0.4 \mathrm{~mm}$ ). The minimal stress bearable for the infinite number of cycles was calculated as $\sigma_{\min (i n f)}$, and its value varied between 184 and $324 \mathrm{MPa}$. Thus, it can be noted that the fatigue strength of the sleeves made of the maraging steel 1.2709 using AM technology, is considerably higher than that of samples for tensile stress.

Figure 14 presents S-N graph with statistical analysis for the sleeves after heat treatment at $490^{\circ} \mathrm{C}$ during $6 \mathrm{~h}$. The porosity of the material was $0.4-0.6 \%$. The double-dotted curve represents the mean fit curve, while the dashed curves correspond with the standard deviation ranges 2SD and 3SD.

As it can be expected, larger percentage of the pores in the material leads to its weakening, perhaps because of more easy crack propagation. Higher porosity $(0.4-0.6 \%)$ provided hoop stress at average $\sigma_{h}=930 \mathrm{MPa}, 490 \mathrm{MPa}$, and $300 \mathrm{MPa}$ after $10^{4}, 10^{5}$, and $10^{6}$ cycles, respectively, while smaller porosity $(0.05-0.1 \%)$ ensured respective values $\sigma_{h}=1100 \mathrm{MPa}, 830 \mathrm{MPa}$, and $730 \mathrm{MPa}$. In case of $10^{6}$ cycles, the hoop stress for smaller porosity is more than twice higher than in case of more porous material.

It is noteworthy that in comparison with tensile S-N fatigue plot, the hoop stress is not linear in logarithmic scale. Both higher fatigue strength and curvature may be attributed to the microstructure of the produced details. Since the material was added layer-by-layer, its strength in different directions can be expected to be different. The damage of the strained sample always takes place along the plane 
between the layers, which may explain smaller bearable stresses than in case of hoop stress directed perpendicularly to them. The detailed study of the microstructure impact is under way.

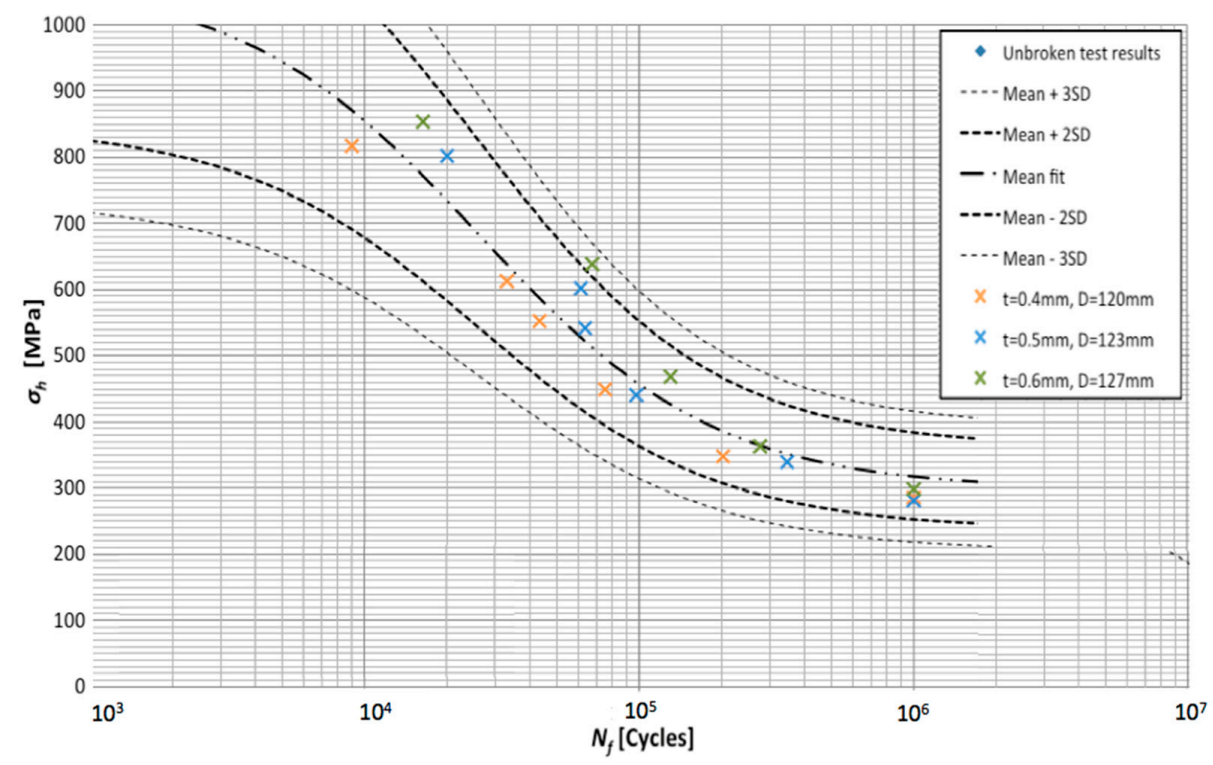

(a)

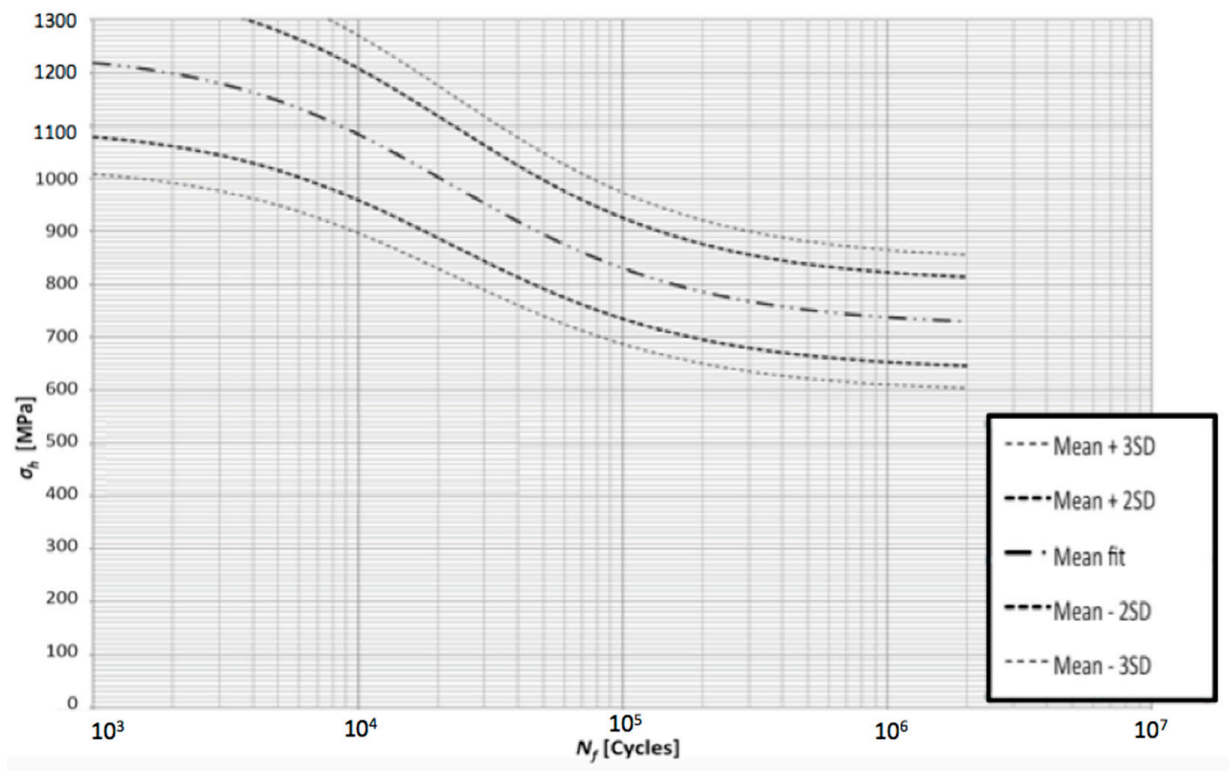

(b)

Figure 14. S-N logarithmic plot of hoop stress for fatigue strength of the tested sleeves, material 1.2709 with different porosity: (a) $0.4-0.6 \%$; (b) $0.05-0.1 \%$.

\subsection{Mössbauer Spectrometry}

Mössbauer spectrometry, as a very common technique in the case of various kinds of steels [20,29-32], has been utilized in order to determine iron-bearing phases. Transmission Mössbauer spectra (TMS) collected at room temperature are presented in Figure 15a,b for the initial powder and 3D printed sleeve, respectively. The spectra were fitted with a set of 5 Voigt-like sextets. G01-G04 components were utilized in order to describe the smeared sub spectrum very characteristic for martensite in maraging steel $[29,30]$. 


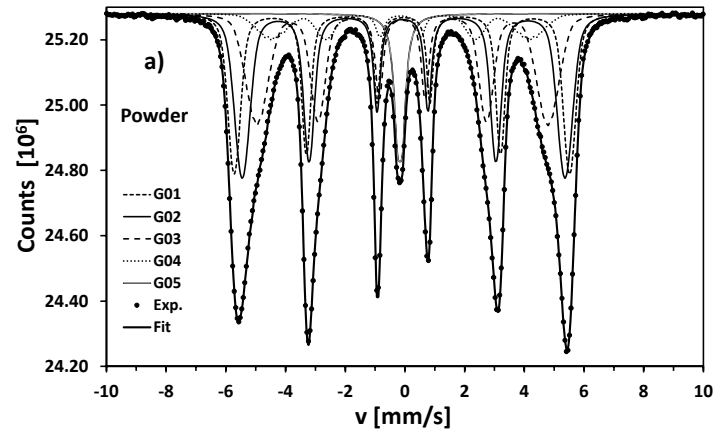

(a)

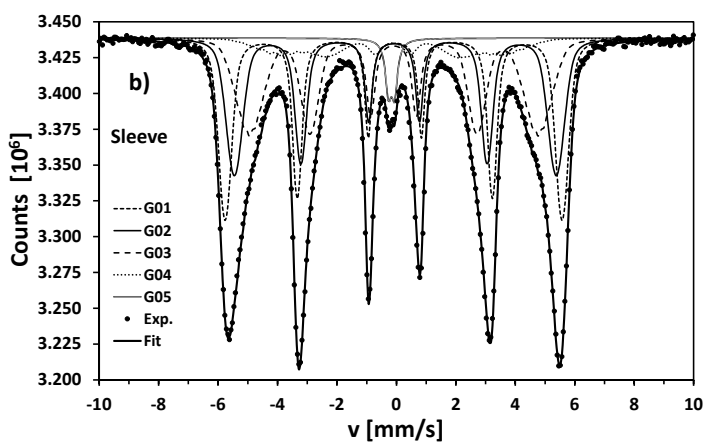

(b)

Figure 15. Room temperature transmission Mössbauer spectra for the initial powder and ready sleeve: (a) initial powder; (b) SLM fabricated sleeve. The components G01-G04 represent martensite while G05 does retained austenite.

According to the Mössbauer data for binary alloys [33] and considering the elemental content of the investigate steel, the subsequent components could be interpreted as different Fe sites (surroundings) in martensite structure (Table 4): with one Co or Ni atom in the first coordination zone (G01), only Fe atoms as the nearest neighbors (G02), one Mo or Ti atom in the first coordination zone (G03), several Mo or Ti atoms as nearest neighbors (G04). These components correspond to four Gaussian distributions of the magnetic hyperfine field $B_{\mathrm{hf}}$ reproducing quasi-continuous, resulting distribution for whole martensite phase (Figure 16).

Each component is characterized by mean value of hyperfine magnetic field distribution $B_{0}$ (from the range $23-35 \mathrm{~T}$ ) and the width of this distribution $D B_{\mathrm{hf}}$ (i.e., standard deviation). The values of these quantities are in general very similar for the rough powder and SLM 3D printed sleeve (Table 4). The most pronounced difference is visible only in the lower mean value of G04 component and in significantly greater width of the distribution. One can also see a reasonable agreement of in values of other hyperfine parameters i.e., isomer shift ( $\delta$, relatively to $\alpha$-Fe calibration foil) and quadrupole splitting $(\Delta E Q)$ as well as in the contributions of the G01-G04 components. In general, both $\delta$ and $\Delta E Q$ are relatively low pointing to the structure of martensite not much deformed with respect to the body centered cubic lattice of $\alpha$-Fe.

Metrologically, more precise comparison would be provided by the analysis of mean values, widths and asymmetries of the whole distributions of the hyperfine magnetic field $P\left(B_{\mathrm{hf}}\right)$ corresponding to the martensite phase in rough powder and SLM 3D printed sleeve. The respective parameters are collected in Table 5 .

Table 4. Contributions and hyperfine parameters of fitted Mössbauer spectra components for initial powder sample and the sleeve (the recognition of martensite-like and austenite-like components according to [29-35]).

\begin{tabular}{|c|c|c|c|c|c|c|}
\hline Component & Phase & $P[\%]$ & $\delta[\mathrm{mm} / \mathrm{s}]$ & $\Delta E Q[\mathrm{~mm} / \mathrm{s}]$ & $B_{0}[\mathrm{~T}]$ & $D B_{\mathrm{hf}}[\mathrm{T}]$ \\
\hline \multicolumn{7}{|l|}{ Powder } \\
\hline G01 & martensite $\mathrm{Fe}-(\mathrm{Co}, \mathrm{Ni})$ sites & $25.8(3)$ & $0.035(1)$ & $-0.051(3)$ & $34.97(2)$ & $0.98(1)$ \\
\hline G03 & martensite $\mathrm{Fe}-(\mathrm{Mo}, \mathrm{Ti})$ sites & $29(2)$ & $0.022(1)$ & $0.009(2)$ & $30.33(1)$ & $1.99(6)$ \\
\hline G04 & martensite Fe-n(Mo,Ti) sites & $8.3(1)$ & $-0.035(2)$ & $0.011(8)$ & $27.0(3)$ & $2.7(1)$ \\
\hline G05 & retained austenite & $5.6(1)$ & $-0.059(1)$ & $0.168(5)$ & - & - \\
\hline G02 & martensite Fe-Fe sites & $28(3)$ & $0.050(1)$ & $0.043(0)$ & $33.7(1)$ & $1.36(8)$ \\
\hline G03 & martensite Fe-(Mo,Ti) sites & $30.0(1)$ & $0.017(2)$ & $0.012(2)$ & $30.23(1)$ & $2.5(1)$ \\
\hline G04 & martensite Fe-n(Mo,Ti) sites & $8.2(1)$ & $-0.045(5)$ & $-0.07(5)$ & $23.11(8)$ & $5(1)$ \\
\hline G05 & retained austenite & $2.4(3)$ & $-0.056(2)$ & $0.21(3)$ & - & - \\
\hline
\end{tabular}




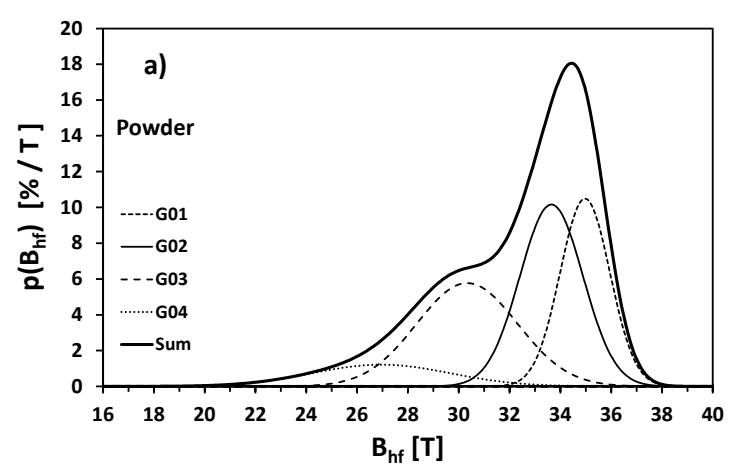

(a)

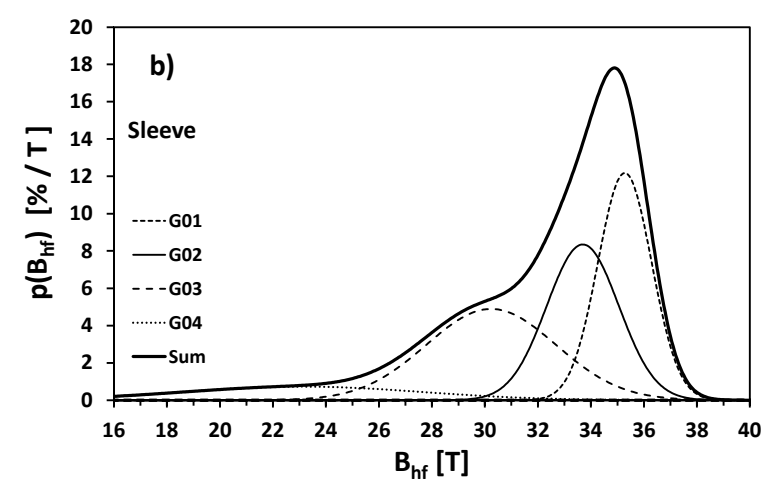

(b)

Figure 16. Distributions of hyperfine magnetic field corresponding to the martensite phase in the respective samples: (a) initial powder; (b) SLM fabricated sleeve.

Table 5. Comparison of magnetic hyperfine field distribution $P\left(B_{\mathrm{hf}}\right)$ parameters corresponding to martensite component (mean value, width-as square root of variance and Pearson-Fisher asymmetry coefficient).

\begin{tabular}{cccc}
\hline Sample $/ B_{\text {hf }}$ Distribution & Mean $<B_{\text {hf }}>[\mathrm{T}]$ & Width $\sigma\left(B_{\text {hf }}\right)[\mathrm{T}]$ & Asymmetry $\tilde{\mu}_{3}$ \\
\hline Powder & $32.41 \pm 0.01$ & $2.98 \pm 0.03$ & $-0.99 \pm 0.04$ \\
Sleeve & $32.24 \pm 0.02$ & $4.03 \pm 0.18$ & $-1.67 \pm 0.25$ \\
\hline
\end{tabular}

The mean values $<B_{\mathrm{hf}}>$ differs very slightly $(32.41 \mathrm{~T}-32.24 \mathrm{~T}=0.17 \mathrm{~T})$ i.e., about $0.5 \%$. Such small difference is a strong proof that the local atomic ordering is very similar in both samples despite significant difference in morphology and metallographic microstructure. Nevertheless, Mössbauer technique was able to detect such subtle changes in structure, because $<B_{\mathrm{hf}}>$ were determined with very good, spectroscopic precision $0.01-0.02 \mathrm{~T}$, i.e., better than $0.03-0.06 \%$. More pronounced difference exhibit the widths of hyperfine magnetic field distributions (defined as a square root of the variance-i.e., standard deviation). In the case of sleeve this width increased by more than $35 \%$. This feature is easy visible directly in Figure 16 and points to the fact that though majority of SLM material reveals almost the same atomic ordering like in the initial powder, in some areas are the clusters of higher concentration of $\mathrm{Mo}, \mathrm{Ti}, \mathrm{Al}$ or $\mathrm{Cu}$. Additional characteristics of the $P\left(B_{\mathrm{hf}}\right)$ shape is Pearson-Fisher asymmetry coefficient:

$$
\widetilde{\mu}_{3}=\int P\left(B_{\mathrm{hf}}\right)\left[\frac{B_{\mathrm{hf}}-\left\langle B_{\mathrm{hf}}\right\rangle}{\sigma\left(B_{\mathrm{hf}}\right)}\right]^{3} d B_{\mathrm{hf}}
$$

which is one of the possible measures of skewness. For both samples it takes negative values, because $P\left(B_{\mathrm{hf}}\right)$ distribution is widened towards left side. Nevertheless, the absolute value of $\widetilde{\mu}_{3}$ is almost $70 \%$ higher for sleeve than for powder. It means that asymmetry coefficient of hyperfine magnetic field distribution is extremely sensitive parameter to subtle changes of atomic ordering in martensite.

The last component in the Mössbauer spectra (G05) is a doublet attributed to the retained austenite. Its content in the rough powder was about 5.6\%, and in 3D printed sleeve-significantly less-c.a. $2.4 \%$. It means, that SLM process facilitates austenite-martensite transformation. Retained austenite in sleeve is characterized by higher value of quadrupole splitting $\Delta E Q$-possible because of stronger deformation of $\gamma$-Fe fcc crystalline structure after SLM. It worth underlining, that in the Mössbauer spectra corresponding to iron oxides were detected (sextets of hyperfine field close to $50 \mathrm{~T}$ ) - nor in the initial powder nor in the sleeves. It is a good proof for the high quality of maraging steel powder and for the effectiveness of argon protective atmosphere during SLM process. 


\section{Conclusions}

The researches were aimed to the strength analysis of the maraging steel details produced out of powder with SLM additive technology. Microsegregation of solute elements caused cellular structure of steel, i.e., martensite inside the cells and retained austenite in intercellular spaces. These features attributed to the strength of the 3D-printed sleeves.

Microstructure of the obtained details revealed differentiated porosity with higher pore percentage at the base, which became stabilized at some reasonably small height. In the material layers adjacent to the supportive structure, some unmolten grains of powder were found, encapsulated into large pores. These structural discontinuities at edges, however, did not affect the strength of the produced details or their fatigue resistance, because the main stress load occurs in the central area of the sleeve. It was confirmed, however, that the overall porosity of the material had direct impact on its strength. Other important finding was made using the analysis of hyperfine magnetic field distributions with transmission Mössbauer spectrometry. It revealed that the applied SLM technology does not change noticeably the martensite structure at atomic level. However, a more than two-fold decrease in the retained austenite content was observed. Moreover, no traces of iron oxides were detected, what is a proof of the efficiency of the argon protective atmosphere.

Some differences between obtained fatigue strength values may be explained considering the layer structure of the SLM-produced details, which require further detailed study. The bearable hoop stress is somewhat larger than the maximum withstandable stress $D B_{\mathrm{hf}}$, which also corresponds with real work conditions. Namely, the tested sleeves produced by AM technology are destined to undergo the pressure load, not strain. The difference takes place despite the uniform conditions of the SLM process and subsequent procedures aimed to unify the material structure.

The analysis proved that the precipitation hardening process increased microhardness of sleeves from ca. $350 \mathrm{HV}$ up to ca. $400 \mathrm{HV}$, and subsequent surface treatment increased it further above $500 \mathrm{HV}$ (hardness of modified layer was above $600 \mathrm{HV}$ ). The treatment had also some positive impact on the grain structure of the material increasing its strength.

The results proved that in case of sleeves, one-sided tensile load is substantially different from the one in real work conditions. The fatigue strength of the sleeves made out of the maraging steel 1.2709 using AM technology, is considerably higher than that of the sleeves shaped as a standard samples for tensile stress. It can be attributed to the directed material structure shaped during 3D scanning.

Author Contributions: Conceptualization, Z.S. and P.T.; methodology, P.B., K.W. and T.S.; validation, Z.S., K.W., M.R. and T.S.; formal analysis, P.T., K.W. and Z.S.; investigation, P.T., P.B., K.W. and T.S.; resources, P.T., P.B. and K.W.; data curation, Z.S. and K.W.; writing—original draft preparation, M.R.; writing-review and editing, P.T., Z.S. and T.S.; visualization, P.B. and M.R.; supervision, Z.S. All authors have read and agreed to the published version of the manuscript.

Funding: This research was funded by European Regional Development Fund, grant number POIR.01.02.00-00-0010/15.

Acknowledgments: The researches were made in frames of project New generation of the hydraulic cylinder FBW made with application of Additive Manufacturing and machining technology at low temperatures (crygenics), Activity 1.2 of Sector Programs B+R, POIR 2014-2020, project No. POIR.01.02.00-00-0010/15.

Conflicts of Interest: The authors declare no conflict of interest.

\section{References}

1. Xue, L. Chapter 16-Laser Consolidation-A Rapid Manufacturing Process for Making Net-Shape Functional Components. In Advances in Laser Materials Processing: Technology, Research and Applications, 2nd ed.; Lawrence, J., Ed.; Woodhead Publishing: London, UK, 2018; pp. 461-505.

2. Li, Z.; Xu, R.; Zhang, Z.; Kucukkoc, I. The influence of scan length on fabricating thin-walled components in selective laser melting. Int. J. Mach. Tools Manuf. 2018, 126, 1-12. [CrossRef] 
3. Shipley, H.; McDonnell, D.; Culleton, M.; Coull, R.; Lupoi, R.; O’Donnell, G.; Trimble, D. Optimisation of process parameters to address fundamental challenges during selective laser melting of Ti-6Al-4V: A review. Int. J. Mach. Tools Manuf. 2018, 128, 1-20. [CrossRef]

4. Doubenskaia, M.; Domashenkov, A.; Smurov, I.; Petrovskiy, P. Study of Selective Laser Melting of intermetallic TiAl powder using integral analysis. Int. J. Mach. Tools Manuf. 2018, 129, 1-14. [CrossRef]

5. Xia, M.; Gu, D.; Yu, G.; Dai, D.; Chen, H.; Shi, Q. Porosity evolution and its thermodynamic mechanism of randomly packed powder-bed during selective laser melting of Inconel 718 alloy. Int. J. Mach. Tools Manuf. 2017, 116, 96-106. [CrossRef]

6. Ziółkowski, G.; Chlebus, E.; Szymczyk, P.; Kurzac, J. Application of X-ray CT method for discontinuity and porosity detection in 316L stainless steel parts produced with SLM technology. Arch. Civ. Mech. Eng. 2014, 14, 608-614. [CrossRef]

7. Tyczynski, P.; Siemiatkowski, Z.; Rucki, M. Analysis of the drill base body fabricated with Additive Manufacturing technology. In Proceedings of the Euspen's 18th International Conference, Venice, Italy, 4-8 June 2018; pp. 287-288.

8. Zhang, J.; Tai, W.G.; Wang, H.; Kumar, A.S.; Lu, W.F.; Fuh, J.Y.H. Magnetic abrasive polishing of additively manufactured 316L stainless steel parts. In Proceedings of the Euspen's 18th International Conference, Venice, Italy, 4-8 June 2018; pp. 401-402.

9. Ribezzo, A.; Calignano, F.; Salmi, A.; Atzeni, E.; Pietrobono, F.; Trovalusci, F.; Rubino, G. Finishing of metal additive manufactured parts by abrasive fluidized bed machining. In Proceedings of the Euspen's 18th International Conference, Venice, Italy, 4-8 June 2018; pp. 271-272.

10. Mutua, J.; Nakata, S.; Onda, T.; Chen, Z.C. Optimization of selective laser melting parameters and influence of post heat treatment on microstructure and mechanical properties of maraging steel. Mater. Des. 2018, 139, 486-497. [CrossRef]

11. Suryawanshi, J.; Prashanth, K.G.; Ramamurty, U. Tensile, fracture, and fatigue crack growth properties of a 3D printed maraging steel through selective laser melting. J. Alloys Compd. 2017, 725, 355-364. [CrossRef]

12. Stern, F.; Kleinhorst, J.; Tenkamp, J.; Walther, F. Investigation of the anisotropic cyclic damage behavior of selective laser melted AISI 316L stainless steel. Fatigue Fract. Eng. Mater. Struct. 2019, 42, 2422-2430. [CrossRef]

13. Santos, L.M.S.; Ferreira, J.A.M.; Borrego, L.P.; Costa, J.D.; Capela, C.; de Jesus, J. Fatigue crack propagation along interfaces of selective laser melting steel hybrid parts. Fract. Eng. Mater. Struct. 2019, 42, 2431-2440. [CrossRef]

14. Nguyen, Q.B.; Luu, D.N.; Nai, S.M.L.; Zhu, Z.; Chen, Z.; Wei, J. The role of powder layer thickness on the quality of SLM printed parts. Arch. Civ. Mech. Eng. 2018, 18, 948-955. [CrossRef]

15. Fatemi, A.; Molaei, R.; Simsiriwong, J.; Sanaei, N.; Pegues, J.; Torries, B.; Nam, P.; Shamsaei, N. Fatigue behaviour of additive manufactured materials: An overview of some recent experimental studies on Ti-6Al-4V considering various processing and loading direction effects. Fatigue Fract. Eng. Mater. Struct. 2019, 42, 991-1009. [CrossRef]

16. Tan, C.; Zhou, K.; Ma, W.; Zhang, P.; Kuang, T. Microstructural evolution, nanoprecipitation behavior and mechanical properties of selective laser melted high-performance grade 300 maraging steel. Mater. Des. 2017, 134, 23-34. [CrossRef]

17. EPMA. Introduction to Additive Manufacturing Technology. Available online: https://futurerobotics. files.wordpress.com/2015/10/epma_introduction_to_additive_manufacturing_technology.pdf (accessed on 9 May 2020).

18. Damon, J.; Hanemann, T.; Dietrich, S.; Graf, G.; Lang, K.H.; Schulze, V. Orientation dependent fatigue performance and mechanisms of selective laser melted maraging steel X3NiCoMoTi18-9-5. Int. J. Fatigue 2019, 127, 395-402. [CrossRef]

19. Antaki, G.A. Piping and Pipeline Engineering: Design, Construction, Maintenance, Integrity and Repair; Marcel Deckker, Inc.: New York, NY, USA, 2003.

20. Siemiątkowski, Z.; Szumiata, T.; Gzik-Szumiata, M.; Martynowski, R.; Rucki, M. Application of the microscopic and Mössbauer studies to the analysis of a marine diesel engine crankshaft. J. Mar. Eng. Technol. 2018, 17, 160-167. [CrossRef]

21. Szumiata, T.; Rachwał, M.; Magiera, T.; Brzózka, K.; Gzik-Szumiata, M.; Gawroński, M.; Górka, B.; Kyzioł-Komosińska, J. Iron-containing phases in metallurgical and coke dusts as well as in bog iron ore. Nukleonika 2017, 62, 187-195. [CrossRef] 
22. DebRoy, T.; Wei, H.L.; Zuback, J.S.; Mukherjee, T.; Elmer, J.W.; Milewski, J.O.; Beese, A.M.; Wilson-Heid, A.; De, A.; Zhang, W. Additive manufacturing of metallic components-Process, structure and properties. Prog. Mater. Sci. 2018, 92, 112-224. [CrossRef]

23. Mittemeijer, E.J.; Somers, M.A.J. Thermochemical Surface Engineering of Steels: Improving Materials Performance; Woodhead Publishing: London, UK, 2015. [CrossRef]

24. Jacquet, P.; Coudert, J.B.; Lourdin, P. How different steel grades react to a salt bath nitrocarburizing and post-oxidation process: Influence of alloying elements. Surf. Coat. Technol. 2011, 205, 4064-4067. [CrossRef]

25. Bosslet, J.; Kreutz, M. TUFFTRIDEß-QPQ-Process: Technical Information; Duferrit Gmbh: Mannheim, Germany, 2018.

26. Hagedorn-Hansen, D.; Bezuidenhout, M.B.; Dimitrov, D.M.; Oosthuizen, G.A. The effects of selective laser melting scan strategies on deviation of hybrid parts. S. Afr. J. Ind. Eng. 2017, 28, 200-212. [CrossRef]

27. Mooney, B.; Kourousis, K.I.; Raghavendra, R. Plastic anisotropy of additively manufactured maraging steel: Influence of the build orientation and heat treatments. Addit. Manuf. 2019, 25, 19-31. [CrossRef]

28. Meneghetti, G.; Rigon, D.; Gennari, C. An analysis of defects influence on axial fatigue strength of maraging steel specimens produced by additive manufacturing. Int. J. Fatigue 2019, 118, 54-64. [CrossRef]

29. Mashlan, M.; Linderhof, F.; Davidova, M.; Kubickova, H.; Zemtsova, E. Changes of phase composition of maraging steel 1.2709 during selective laser melting. Hyperfine Interact. 2020, 241, 1-8. [CrossRef]

30. da Silva, J.J.M.; de Vasconcelos, I.F.; da Silva, F.I.S.; Ribeiro, T.S.; de Abreu, H.F.G. An Atomic Redistribution Study of the $440^{\circ} \mathrm{C}$ Ageing Kinetics in Maraging-300 Steel. Mater. Res. 2019, 22, e20180230. [CrossRef]

31. Li, X.; Yin, Z. Mössbauer study of the aging behavior of 18Ni(350) maraging steel. Mater. Lett. 1995, 24, 235-238. [CrossRef]

32. Li, X.D.; Yin, Z.D.; Li, H.B.; Lei, T.C.; Liu, M.L.; Liu, X.W.; Jin, M.Z. Mössbauer study of the early stages of aging in 18Ni(350) maraging steel. Mater. Chem. Phys. 1993, 33, 277-280. [CrossRef]

33. Vincze, I.; Campbell, A. Mossbauer measurements in iron based alloys with transition metals. J. Phys. F Metal Phys. 1973, 3, 647-663. [CrossRef]

34. Yoshida, Y.; Langouche, G. Mössbauer Spectroscopy: Tutorial Book; Yoshida, Y., Langouche, G., Eds.; Springer: Berlin/Heidelberg, Germany, 2013.

35. Olina, A.; Píška, M.; Petrenec, M.; Hervoches, C.; Beran, P.; Pechoušek, J.; Král, P. Assessment of Retained Austenite in Fine Grained Inductive Heat Treated Spring Steel. Materials 2019, 12, 4063. [CrossRef] 